\title{
Ảnh hưởng của hàm lượng bột đá đến tính chất của vật liệu composite nhựa gố trên cơ sở nhựa polyethylene tái chế
}

\author{
Nguyễn Quý An ${ }^{1 *}$, Đào Quốc Hùng ${ }^{1}$, Trịnh Minh Đạt ${ }^{1}$, Lê Văn Long ${ }^{1}$ \\ ${ }^{1}$ Trung tâm Vật liệu hữu cơ \& Hóa phẩm xây dựng, Viện Vật liệu xây dựng
}

TỪ KHOÁ

Vật liệu composite nhựa gỗ

Bột đá

\begin{abstract}
TÓM TẮT
Trong sản xuất vật liệu composite nhựa gỗ, để giảm chi phí sản xuất và cải thiện một số tính chất của vật liệu, việc sử dụng các chất độn khoáng là rất cần thiết. Trong bài báo này, ảnh hưởng của bột đá đến tính chất của vật liệu composite nhựa gỗ được chế tạo trên cơ sở nhựa polyethylene tái chế và bột gỗ đã được nghiên cứu. Kết quả nghiên cứu cho thấy: việc bổ sung bột đá với hàm lượng phù hợp đã cải thiện khả năng gia công của vật liệu ở trạng thái nóng chảy, cũng như các tính chất cơ lý khác như độ bền kéo, độ bền uốn. Khi bổ sung bột đá với hàm lượng $15 \%$ khối lượng so với bột gỗ và nhựa (pkl), vật liệu cho tính chất tối ưu nhất với độ bền kéo tăng khoảng $20 \%$ (từ 10,84 MPa lên 13,16 MPa), độ bền uốn tăng khoảng $12 \%$ (từ 21,12 MPa lên 23,70 MPa), so với mẫu đối chứng không sử dụng bột đá. Khi không sử dụng bột đá, trong lòng vật liệu tồn tại nhiều khoảng trống có thể quan sát được qua ảnh hiển vi điện tử quét (SEM), những khoảng trống này là nguyên nhân của độ hút nước cao cũng như khối lượng riêng kém hơn so với mẫu sử dụng bột đá với hàm lượng phù hợp.
\end{abstract}

\section{ABSTRACT}

To reduce the cost and improve the performance of wood plastic composite (WPC), the use of mineral fillers is necessary. In this paper, the effect of the additive amount of limestone powder on preparation and mechanical properties of recycled polyethylene-based WPC were studied. The results showed that calcium carbonate can improve preparation and mechanical properties effectively. When adding calcium carbonate with $15 \mathrm{wt} \%$ of wood powder and polymer (pkl), the material gave the best properties with an increase of about $20 \%$ in tensile strength (from $10.84 \mathrm{MPa}$ to $13.16 \mathrm{MPa}$ ), about $12 \%$ increase in flexural strength (from 21.12 MPa to 23.70 MPa), compared with the reference sample without calcium carbonate. In the control sample without calcium carbonate, many gaps could be observed by scanning electron microscopy (SEM), these gaps were the cause of the high water absorption as well as the lower density compared to the sample with $15 \mathrm{wt} \%$ calcium carbonate.

\section{Giới thiệu chung}

Trong những năm gần đây, vật liệu composite nhựa gỗ đang được tập trung nghiên cứu và sử dụng nhiều do có các tính chất nổi bật như: bền khi sử dụng, tuổi thọ sản phẩm cao, có độ cứng cao, có kích thước ổn định hơn, không bị xuất hiện các vết rạn nứt,....thân thiện môi trường do không phát thải formaldehyt. Trong lĩnh vực vật liệu xây dựng, vật liệu composite nhựa gỗ thường được sử dụng với nhiều loại hình sản phẩm như ván sàn, lan can, cầu thang, hàng rào, tấm ốp trang trí, .... Trong quá trình sản xuất, để hạn chế quá trình co ngót, tăng độ cứng, độ chịu mài mòn cũng như giảm chi phí và nâng cao hiệu quả về kinh tế thì việc sử dụng các chất độn khoáng là rất cần thiết.

Chất độn khoáng như bột talc, bột đá và wollastonite có thể cải thiện độ bền uốn, giảm biến dạng dưới tác động của tải trọng, nâng cao độ cứng và tính chất chống cháy của vật liệu. Ngoài ra, chất độn khoáng còn có tác dụng cải thiện tính chất gia công thông qua việc hoạt động giống như phụ gia bôi trơn [1] [2].

Trong ngành công nghiệp sản xuất và chế tạo vật liệu chất dẻo nói chung và vật liệu composite nhựa gỗ nói riêng, những chất độn khoáng vô cơ như bột talc và bột đá được sử dụng phổ biến nhất. Trong đó, được sử dụng phổ biến hơn cả là bột đá do những tính chất như: giá thành rẻ, không độc hại, và trữ lượng lớn trong tự nhiên [3]. Ở Việt Nam, những nghiên cứu về sử dụng chất độn cho vật liệu composite nhựa gỗ còn ít, các nghiên cứu chủ yếu tập trung vào việc xác định ảnh hưởng của tỷ lệ bột gỗ/nhựa, chế độ gia công và một số phụ gia khác, ...

Trong nghiên cứu này, nhóm nghiên cứu sẽ khảo sát ảnh hưởng của hàm lượng bột đá đến tính chất lưu biến và một số tính chất cơ lý của vật liệu composite nhựa gỗ trên cơ sở nhựa polyethylene tái chế. Từ kết quả nghiên cứu sẽ tìm được hàm lượng bột đá phù hợp để giảm giá thành và cải thiện các tính chất của vật liệu composite nhựa 
gỗ. Kết quả nghiên cứu sẽ là cơ sở để lựa chọn tỷ lệ giữa các thành phần trong nghiên cứu sản xuất thử nghiệm ở quy mô pilot.

\section{Nguyên vật liệu và phương pháp nghiên cứu}

2.1. Nguyên liệu, hóa chất

Một số nguyên liệu chính sử dụng trong nghiên cứu được thể hiện trên Bảng 1.

Bảng 1. Nguyên liệu chính sử dụng trong nghiên cứu.

\begin{tabular}{|c|c|c|c|}
\hline STT & $\begin{array}{l}\text { Nguyên } \\
\text { liệu }\end{array}$ & Tính chất & Xuất xứ \\
\hline 1 & $\begin{array}{l}\text { Nhựa } \\
\text { polyethylene } \\
\text { tái chế }\end{array}$ & $\begin{array}{l}\text { - Khối lượng riêng: } 1,001 \mathrm{~g} / \mathrm{cm}^{3} \\
\text { - Chỉ số chảy: 1,54 g/10 phút } \\
\text { - Độ bền kéo: 17,57 MPa }\end{array}$ & $\begin{array}{l}\text { Công ty Cổ phần } \\
\text { Vĩnh Thành }\end{array}$ \\
\hline 2 & Bột gỗ & $\begin{array}{l}\text { - Kích thước lọt sàng: } 315 \mu \mathrm{m} \\
\text { - Độ ẩm: < 5\% } \\
\text { - Hàm lượng tro: < 5\% }\end{array}$ & $\begin{array}{l}\text { Công ty cổ phần } \\
\text { bột gỗ NK Việt } \\
\text { Nam }\end{array}$ \\
\hline 3 & Bột đá & $\begin{array}{l}\text { - Kích thước hạt trung bình: } \\
25,85 \mu \mathrm{m} \\
\text { - Khối lượng riêng: } 2,7 \mathrm{~g} / \mathrm{cm}^{3}\end{array}$ & $\begin{array}{c}\text { Công ty bột đá vôi } \\
\text { trắng siêu mịn } \\
\text { Nghệ An }\end{array}$ \\
\hline 4 & $\begin{array}{l}\text { Phụ gia trợ } \\
\text { tương hợp }\end{array}$ & $\begin{array}{l}\text { - Khối lượng riêng: } 0,948 \mathrm{~g} / \mathrm{cm}^{3} \\
\text { - Chỉ số chảy: } 25,0 \mathrm{~g} / 10 \text { phút } \\
\text { - Độ bền kéo: } 23,0 \mathrm{MPa}\end{array}$ & Hãng BYK \\
\hline 5 & $\begin{array}{l}\text { Phụ gia bôi } \\
\text { trơn }\end{array}$ & $\begin{array}{l}\text { - Khối lượng riêng: } 0,941 \mathrm{~g} / \mathrm{cm}^{3} \\
\text { - Nhiệt độ nóng chảy: } 69^{\circ} \mathrm{C}\end{array}$ & Trung Quốc \\
\hline
\end{tabular}

\subsection{Chế tạo vật liệu composite nhựa gỗ}

Tấm vật liệu composite nhựa gỗ chế tạo theo đơn phối liệu trên Bảng 2 .

Trong nghiên cứu này, sử dụng bột độn có hàm lượng thay đổi từ 0 đến 30 phần trăm khối lượng so với bột gỗ và nhựa (pkl) và các thành phần khác được cố định như trong Bảng 2.

Bảng 2. Tỷ lệ hỗn hợp các thành phần.

\begin{tabular}{|c|c|c|c|c|c|}
\hline \multirow{2}{*}{ STT } & \multicolumn{5}{|c|}{ Thành phần (phần khối lượng) } \\
\cline { 2 - 6 } & Bột gỗ & $\begin{array}{c}\text { Polyethylene } \\
\text { tái chế }\end{array}$ & $\begin{array}{c}\text { Phụ gia } \\
\text { bôi trơn }\end{array}$ & $\begin{array}{c}\text { Phụ gia } \\
\text { tương hợp }\end{array}$ & Bột đá \\
\hline 1 & 60 & 40 & 2 & 4 & 0 \\
\hline 2 & 60 & 40 & 2 & 4 & 5 \\
\hline 3 & 60 & 40 & 2 & 4 & 10 \\
\hline 4 & 60 & 40 & 2 & 4 & 15 \\
\hline 5 & 60 & 40 & 2 & 4 & 20 \\
\hline 6 & 60 & 40 & 2 & 4 & 30 \\
\hline
\end{tabular}

Hạt nhựa polyethylene tái chế và bột gỗ và các phụ gia được trộn hợp ở trạng thái nóng chảy trên máy trộn kín Hakee QC 600 tại nhiệt độ $180^{\circ} \mathrm{C}$ với tốc độ trục 50 vòng/phút trong thời gian 5 phút.

Hỗn hợp vật liệu sau đó được ép tạo hình nhiệt trên máy ép thủy lục YLJ-HP88V với lực ép $50 \mathrm{kN}$ tại nhiệt độ $180^{\circ} \mathrm{C}$ trong thời gian 5 phút.

\subsection{Phương pháp xác định các tính chất của vật liệu composite nhựa gỗ}

Xác định tính chất lưu biến tại trạng thái nóng chảy trên thiết bị trộn kín hai trục Hakee Rheomix QC600.

Xác định độ bền kéo theo ISO 527-1 trên thiết bị Intron 3382 với tốc độ kéo $5 \mathrm{~mm} /$ phút, kết quả là giá trị trung bình của 5 thanh mẫu thử.

Xác định độ bền uốn theo ISO 178 trên thiết bị Instron 3382 với tốc độ uốn $5 \mathrm{~mm} /$ phút, kết quả là giá trị trung bình của 5 thanh mẫu thử.

Xác định độ bền va đập Chapy theo ISO 179-1 với mẫu thử có khía trên thiết bị Ceast 9050, là giá trị trung bình của 5 thanh mẫu thử.

Xác định khối lượng riêng theo các quy định của ISO 1183-1.

Phân tích cấu trúc vật liệu bằng kính hiển vi điện tử quét (SEM) trên thiết bị JSM-6360LV.

\section{Kết quả và thảo luận}

\section{1. Ảnh hưởng của hàm lượng bột đá tới tính chất lưu biến của vật liệu}

Trong chế tạo vật liệu composite nhựa gỗ, tính chất lưu biến có ảnh hưởng tới quá trình gia công cũng những tính chất của vật liệu. Độ nhớt tại trạng thái nóng chảy quá cao làm cho vật liệu khó điền đầy khuôn và tăng chi phí cho năng lượng cần thiết; mặt khác, độ nhớt nóng chảy quá thấp lại hình thành nên vật liệu với tính chất kém hơn [3].

Kết quả nghiên cứu ảnh hưởng của bột đá đến tính lưu biến của vật liệu ở trạng thái nóng chảy có thể được phản ánh qua thông số mô men trong quá trình trộn hợp như trong Hình 1.

Kết quả trên Hình 1 và Bảng 3 cho thấy: khi bổ sung một lượng nhỏ bột đá (5 pkl), giá trị mô men ở trạng thái cân bằng giảm mạnh từ 11,6 N.m xuống còn 8,2 N.m. Sau đó, giá trị mô men có xu hướng tăng khi tăng hàm lượng bột đá tới 15 pkl, tuy nhiên khi sử dụng hàm lượng lớn hơn 15 pkl, giá trị mô men không tăng nữa.

\section{2 Ảnh hưởng của hàm lượng bột đá đến tính chất vật lý của vật liệu}

Khi sử dụng thêm bột đá vào vật liệu composite nhựa gỗ sẽ làm thay đổi một số thông số vật lý của vật liệu như khối lượng riêng, độ hấp thụ nước. Kết quả nghiên cựu ảnh hưởng của hàm lượng bột đá đến khối lượng riêng và độ hấp thụ nước của vật liệu như trên Hình 2, Hình 3.

Kết quả trên Hình 2 cho thấy: khối lượng riêng của vật liệu composite nhựa gỗ có xu hướng tăng khi hàm lượng bột đá sử dụng 
tăng. Điều này có thể giải thích như sau: khi hàm lượng bột gỗ sử dụng lớn hơn 40 \%, nhóm chức hydroxyl trong cellulose có thể hình thành các liên kết hydro nội phân tử và liên phân tử, do đó dễ dàng kết tụ và hình thành những khoảng trống nhỏ giữa các sợi gỗ [4]. Trong nghiên cứu này, sử dụng bột đá có kích thước nhỏ hơn rất nhiều so với bột gỗ nên trong quá trình trộn hợp, có thể bột đá sẽ điền đầy vào những khoảng trống nhỏ tồn tại giữa các sợi gỗ nói trên, ngoài ra, bột gỗ có khối lượng riêng lớn hơn đáng kể so với bột đá do

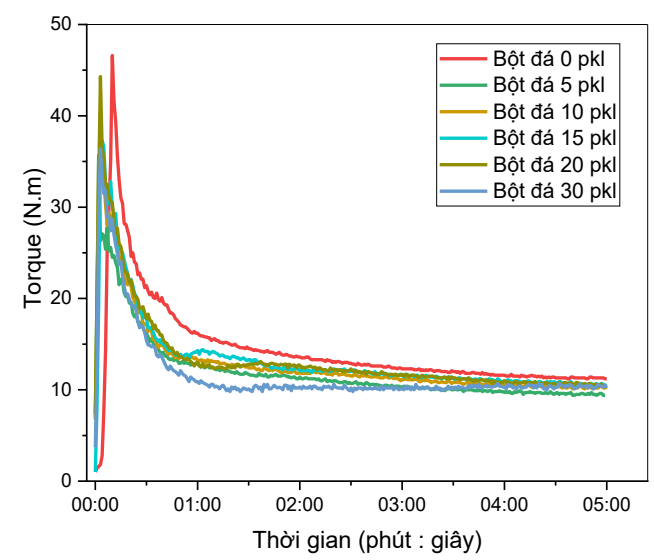

đó làm cấu trúc của vật liệu chặt chẽ hơn và tăng khối lượng riêng của vật liệu.

Kết quả phân tích ảnh SEM như trên Hình 3 cho thấy: đối với vật liệu không sử dụng bột đá có các khoảng trống (Hình 3.a), khi bổ sung bột đá với hàm lượng 15 pkl thì cấu trúc của vật liệu đồng đều hơn và giảm hẳn các lỗ trống nhỏ, điều này chứng tỏ rằng bột đá đã điền đầy vào các khoảng trống và làm cho vật liệu có câu trúc chặt chẽ hơn.

Bảng 3. Mô men xoắn ở trạng thái cân bằng

\begin{tabular}{|c|c|c|}
\hline STT & $\begin{array}{c}\text { Hàm lượng bột đá } \\
\text { (pkl) }\end{array}$ & $\begin{array}{c}\text { Mô men xoắn cân } \\
\text { bằng } \\
\text { (N.m) }\end{array}$ \\
\hline 1 & 0 & 11,6 \\
\hline 2 & 5 & 8,2 \\
\hline 3 & 10 & 9,9 \\
\hline 4 & 15 & 10,5 \\
\hline 5 & 20 & 10,3 \\
\hline 6 & 30 & 10,2 \\
\hline
\end{tabular}

Hình 1. Ảnh hưởng của hàm lượng bột đá tới tính lưu biến ở trạng thái nóng chảy.

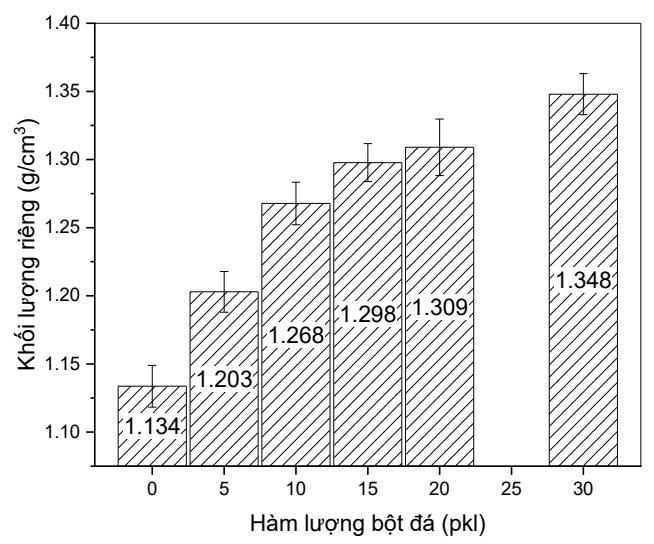

Hình 2. Ảnh hưởng của hàm lượng bột đá đến khối lượng riêng của vật liệu.

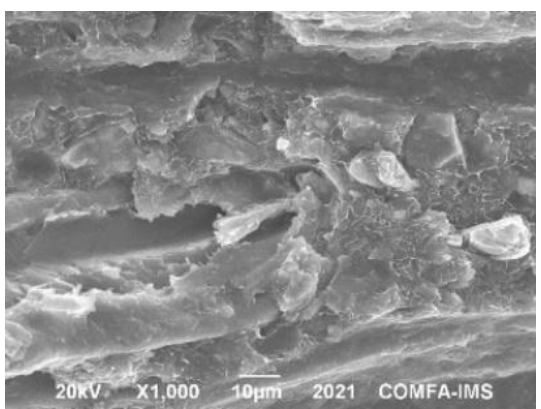

(a) 0 pkl bột đá

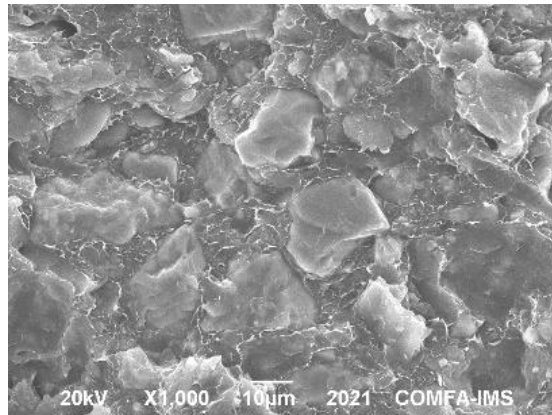

(b) 15 pkl bột đá

Hình 3. Ảnh SEM cấu trúc vật liệu với hàm lượng bột đá khác nhau. 
Ngoài ra, kết quả nghiên cứu ảnh hưởng của hàm lượng bột gỗ đến độ hấp thụ nước của vật liệu như trên Hình 4 cũng cho thấy: độ hấp thụ nước của vật liệu giảm khi hàm lượng bột đá sử dụng tăng từ 5 lên 20 pkl. Điều này chứng tỏ rằng: việc sử dụng bột đá ở hàm lượng thích hợp sẽ tạo ra vật liệu với cấu trúc chặt chẽ hơn và làm giảm độ hấp thụ nước. Tuy nhiên, khi sử dụng bột đá với hàm lượng 30 pkl, độ hấp thụ nước có dấu hiệu tăng trở lại.

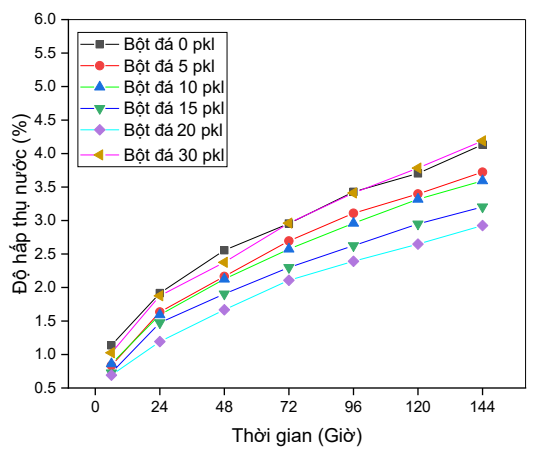

Hình 4. Ảnh hưởng của hàm lượng bột đá đến độ hấp thụ nước của vật liệu.

\section{3. Ảnh hưởng của hàm lượng bột đá đến tính chất cơ học của vật liệu}

Bổ sung bột đá với hàm lượng từ 5 đến 15 pkl, cấu trúc của vật liệu trở lên đồng nhất hơn, do đó có thể cải thiện tính chất cơ học của vật liệu. Kết quả nghiên cứu ảnh hưởng của hàm lượng bột đá đến tính chất kéo, uốn và độ bền và đập của vật liệu được thể hiện như trên Hình 5, Hình 6 và Hình 7.

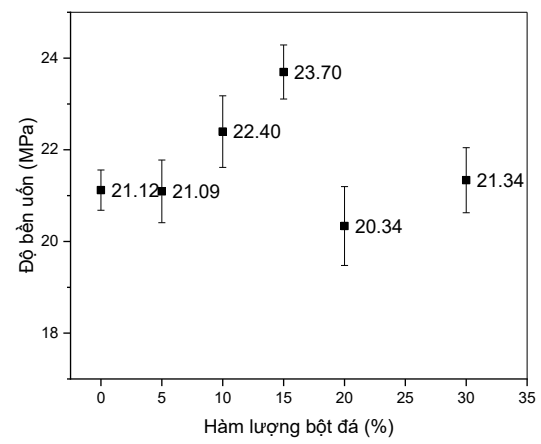

Hình 5. Ảnh hưởng của hàm lượng bột đá đến độ bền uốn của vật liệu.

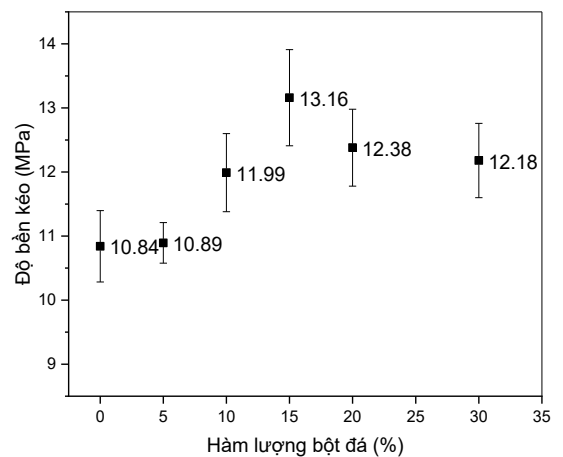

Hình 6. Ảnh hưởng của hàm lượng bột đá đến độ bền kéo của vật liệu.
Từ kết quả nghiên cứu trên Hình 5 , Hình 6 cho thấy: khi tăng hàm lượng bột đá từ 0 lên 15 pkl, độ bền kéo tăng từ 10,84 lên 13,16 MPa (tăng 21 \%), độ bền uốn tăng từ 21,12 MPa lên 23,70 MPa (tăng 12 \%). Khi hàm lượng bột đá lớn hơn giá trị 15 pkl, cả hai tính chất đều có xu hướng giảm xuống. Điều này có thể là do khi hàm lượng bột đá sử dụng lớn hơn 15 pkl, bột đá không còn phân tán đồng đều trong vật liệu, kết tụ lại với nhau tạo ra các khuyết tật, dẫn tới làm giảm cường độ uốn, kéo.

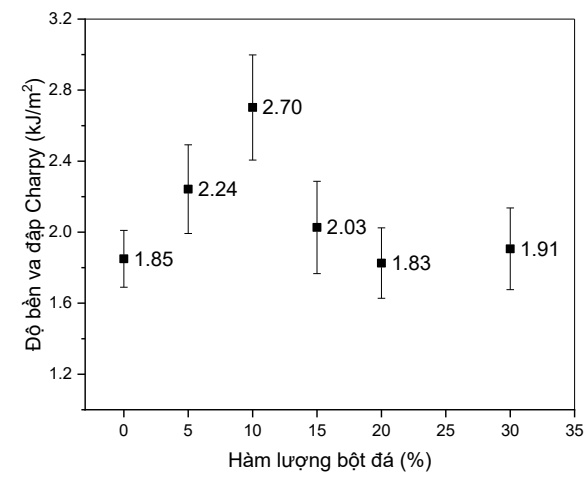

Hình 7. Ảnh hưởng của hàm lượng bột đá đến độ bền va đập charpy của vật liệu.

Kết quả ảnh hưởng của hàm lượng bột đá đến độ bền va đập như trên Hình 7 cho thấy: khi hàm lượng bột đá tăng, độ bền va đập charpy tăng và đạt giá trị lớn nhất $2,7 \mathrm{~kJ} / \mathrm{m}^{2}$ tại hàm lượng bột đá 10 pkl, khi hàm lượng bột đá sử dụng lớn hơn 10 pkl, độ bền va đập có xu hướng giảm. Điều này cũng có thể giải thích là do sự kết tụ của bột đá khi sử dụng hàm lượng cao, tuy nhiên, mức độ ảnh hưởng đến độ bền va đập khác so với cường độ uốn và kéo.

Tại hàm lượng bột đá 15 pkl, giá trị độ bền va đập đạt được là $2,03 \mathrm{~kJ} / \mathrm{m}^{2}$ cao hơn so với khi không sử dụng bột đá, các tính chất cơ lý khác đạt giá trị tối ưu nhất.

Từ các kết quả nghiên cứu trên, nhóm nghiên cứu đã lựa chọn hàm lượng bột đá phù hợp nhất sử dụng trong chế tạo vật liệu composite nhựa gỗ là 15 pkl. Tại giá trị này, các tính chất của vật liệu được cải thiện rõ ràng và đạt được như sau:

- Khối lượng riêng $1,298 \mathrm{~g} / \mathrm{cm}^{3}$

- Độ hấp thụ nước sau 24 giờ là $1,47 \%$

- Độ bền kéo 13,16 MPa,

- Độ bền uốn 23,70 MPa

- Độ bền va đập 2,03 MPa

\section{Kết luận}

Trong bài báo này, ảnh hưởng của hàm lượng bột đá đến tính chất cơ lý của vật liệu composite nhựa gỗ trên cơ sở nhựa polyethylene tái chế đã được nghiên cứu. Kết quả nghiên cứu cho thấy: khi bổ sung bột đá với hàm lượng 15 pkl đã làm cải thiện tính chất lưu biến của vật liệu với giá trị mô men xoắn tại trạng thái cân bằng giảm từ 11,6 N.m xuống còn 10,5 N.m, ngoài ra, việc bổ sung 15 pkl bột đá cũng đã làm cho độ bền kéo của vật liệu tăng từ 10,84 MPa lên 13,16 MPa; độ bền uốn tăng từ 21,12 MPa lên 23,7 MPa. Khi hàm 
lượng bột đá vượt quá 15 pkl, các tính chất cơ lý của vật liệu có xu hướng giảm xuống.

Kết quả phân tích ảnh SEM cho thấy rằng: khi bổ sung bột đá với hàm lượng 15 pkl, đã làm cho cấu trúc của vật liệu trở nên đồng nhất hơn, giảm khoảng trống trong cấu trúc vật liệu, qua đó cải thiện một số tính chất cơ học và vật lý của vật liệu.

\section{Tài liệu tham khảo}

[1]. O. Martikka, T. Huuhilo, S. Butylina, and T. Kärki, "The effect of mineral fillers on the thermal properties of wood-plastic composites,"
Wood Material Science \& Engineering, vol. 7, no. 2, pp. 107-114, Jun. 2012, doi: 10.1080/17480272.2012.663408.

[2]. R. A. Ramli, N. Z. Zakaria, U. U. A. Rahman, N. B. A. Bakhtiar, S. N. H. Mustapha, and Y. M. Lian, "Effect of mineral fillers on mechanical, thermal and morphological properties of kenaf recycled polyethylene wood plastic composite," Eur. J. Wood Prod., vol. 76, no. 6, pp. 17371743, Nov. 2018, doi: 10.1007/s00107-018-1356-2.

[3]. C. Hongzhen, K. Yang, and Y. Weiming, "Effects of calcium carbonate on preparation and mechanical properties of wood/plastic composite," vol. 10, pp. 184-190, Jan. 2017, doi: 10.3965/j.ijabe.20171001.2707.

[4]. L. L. Yang, H. Li, and Z. Y. Zhong, "Study on mechanical properties of PP/wood powder composite," Plastics Science and Technology, vol. 38, no. 2, pp. 36-39, 2010. 